\title{
Differential Hall effect profiling of ultrashallow junctions in Sb implanted silicon
}

\author{
T. Alzanki, ${ }^{\text {a) }}$ R. Gwilliam, N. Emerson, and B. J. Sealy \\ Advanced Technology Institute, University of Surrey, Guildford, Surrey, United Kingdom
}

(Received 5 March 2004; accepted 14 July 2004)

\begin{abstract}
A differential Hall effect technique has been developed to obtain doping profiles at a depth resolution down to $2 \mathrm{~nm}$ with junction depths of about $20 \mathrm{~nm}$. We have determined the electrical characteristics of $5 \times 10^{14} \mathrm{Sb}^{+} \mathrm{cm}^{-2}$ implanted in (100) silicon at an energy of $5 \mathrm{keV}$. A comparison was made between carrier concentration profiles and secondary ion mass spectroscopy measurements of the atomic profiles as a function of annealing temperature. We have profiled single energy implants of antimony and also double implants; the latter enables complete profiles to be measured down to the background level of about $10^{18} \mathrm{~cm}^{-3}$. () 2004 American Institute of Physics.
\end{abstract}

[DOI: $10.1063 / 1.1792378]$

Future generations of (CMOS) devices will require the production of ultrashallow junctions $(10-20 \mathrm{~nm})$ for the source/drain extension regions, ${ }^{1}$ but low energy implantation to obtain these layers faces many difficulties. ${ }^{2}$ The electrical characteristics, including profiles, of shallow layers have been measured by spreading resistance but there has been little if any study using differential Hall effect measurements. ${ }^{3,4}$ However, there are difficulties with profiling such shallow layers using the differential Hall effect technique. For example, the anodization process that has been commonly used in the past ${ }^{5}$ does not work well for very thin layers. Also the junction formed as a result of the implantation has a depletion region associated with it which limits the extent of the profile which can be measured. We have considered these problems and have developed a method for determining the electrical profiles by using double implants of antimony and an improved method for removing thin layers $(1-2 \mathrm{~nm})$ uniformly and reproducibly so that the differential Hall technique can be utilised.

$P$-type (100) Si wafers of resistivity of $2-10 \Omega \mathrm{cm}$ were implanted at room temperature with $5 \times 10^{14} \mathrm{Sb}^{+} \mathrm{cm}^{-2}$ at $5 \mathrm{keV}$. To facilitate the measurement of the carrier profile, a second implant of $3 \times 10^{13} \mathrm{Sb}^{+}$at $70 \mathrm{keV}$ was performed into part of the wafer. This produces an antimony concentration of $10^{18}-10^{19} \mathrm{~cm}^{-3}$ in the tail of the $5 \mathrm{keV}$ implant and moves the $n^{+} / p$ junction deep $(\approx 80 \mathrm{~nm})$ into the material. All the implants were performed using a $200 \mathrm{kV}$ Danfysik 1090 accelerator. The wafers were annealed at temperatures of $600-1100{ }^{\circ} \mathrm{C}$ for $10 \mathrm{~s}$ in a flowing nitrogen ambient. Electrical measurements were performed on cloverleaf samples using an Accent HL5900 Hall system with In/Ga eutectic used for ohmic contact formation.

For differential Hall effect profiling, we have developed a native oxide growth and strip process, since the conventional anodization technique ${ }^{5}$ does not give the necessary reproducibility and control at the nanometer level. The process is to immerse the sample into de-ionized water for $10 \mathrm{~s}$, which enables the growth of a very thin oxide. The sample is then washed and dried before measurement of the sheet Hall coefficient and sheet resistance with the oxide in place. Subsequently, the oxide is removed in 5\% buffered hydrofluoric

\footnotetext{
${ }^{a)}$ Electronic mail: t.alzanki@surrey.ac.uk
}

acid and the process of oxidation and measurement repeated until the end of the profile is reached. The total amount of silicon removed is measured using a Rank-Taylor-Hobson Talystep and the etch rate determined knowing the total number of oxidation steps performed. The etch rate (oxide thickness) can be varied over a small range $(0.7-2.5 \mathrm{~nm})$ by changing the time $(5-20 \mathrm{~s})$ that the sample spends in the de-ionized water. The total etch step is measured for each sample and is found to lie in the range $2 \pm 0.3 \mathrm{~nm}$ for the samples studied in this work. The antimony atomic profiles were measured by secondary ion mass spectrometry (SIMS) carried out using a Cameca IMS 6F with a primary beam energy of $1.5 \mathrm{keV} \mathrm{O} \mathrm{O}_{2}^{+}$.

The electrical activation and sheet resistance measured as a function of the annealing temperature for the single energy $5 \mathrm{keV}$ antimony implant is shown in Fig. 1. For the range of annealing conditions investigated, the sheet resistance increases and the electrical activation decreases with increasing annealing temperature. The uncertainty in the measurement of electrical activation is $\pm 2.5 \%$.

We observe a decrease in the electrical activation from $60 \%$ to $16 \%$ and an increase in the sheet resistance from 430 to $770 \Omega$ /square with increasing annealing temperature from 600 to $1100{ }^{\circ} \mathrm{C}$ (Fig. 1). The decrease in activity at

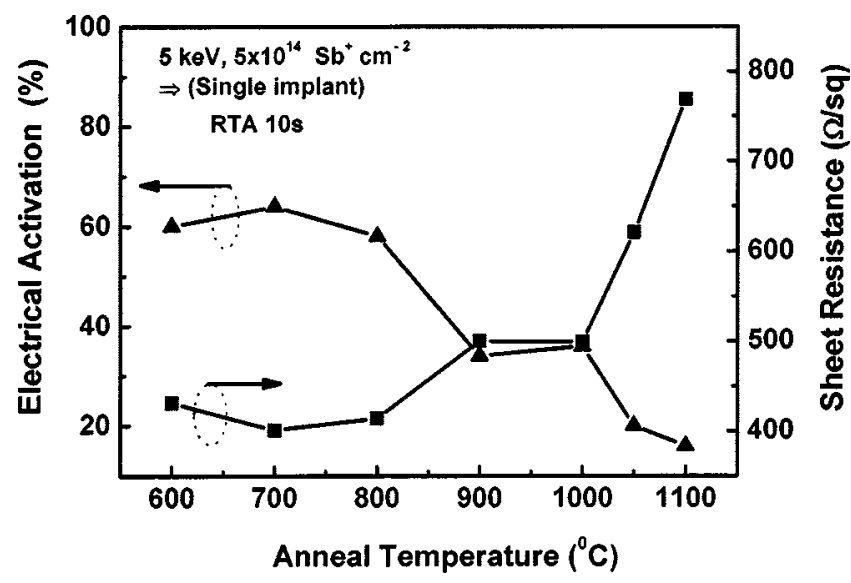

FIG. 1. Electrical activation and sheet resistance as a function of annealing temperature for $5 \mathrm{keV} \mathrm{Sb}$. The annealing time was $10 \mathrm{~s}$. The uncertainty in the measurement of the electrical activation and sheet resistance is $\pm 2.5 \%$. 


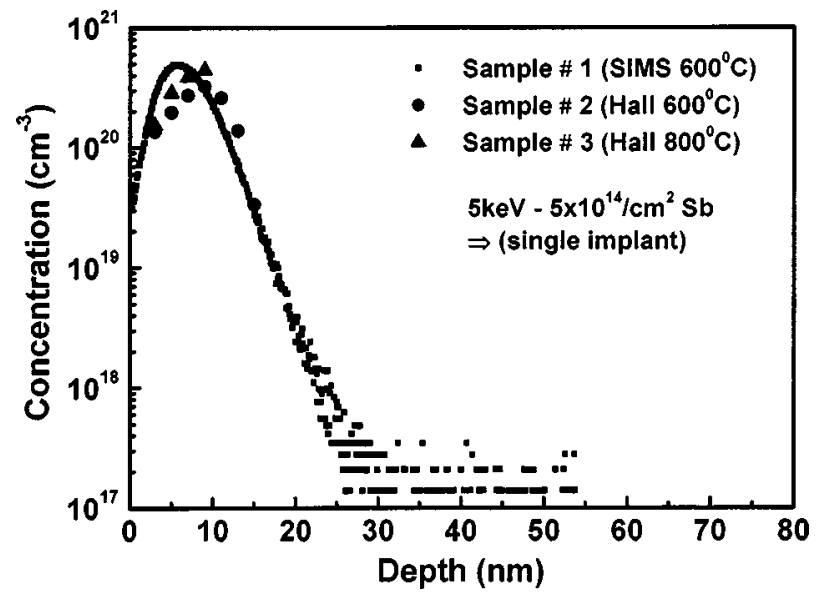

FIG. 2. Carrier concentration profiles for $5 \mathrm{keV}, 5 \times 10^{14} \mathrm{Sb}^{+} \mathrm{cm}^{-2}$ annealed at 600 and $800{ }^{\circ} \mathrm{C}$ with an annealing time of $10 \mathrm{~s}$. A SIMS atomic profile is shown for the $600{ }^{\circ} \mathrm{C}$ anneal. The atomic profiles are identical for asimplanted, 600 and $800^{\circ} \mathrm{C}$.

$1100{ }^{\circ} \mathrm{C}$ is most probably due to outdiffusion since we have observed significant profile broadening for high temperature anneals. The sheet mobility increases from about $50 \mathrm{~cm}^{2} / \mathrm{V} \mathrm{s}$ at $600{ }^{\circ} \mathrm{C}$ to $100 \mathrm{~cm}^{2} / \mathrm{V} \mathrm{s}$ at $1100{ }^{\circ} \mathrm{C}$, which is associated with a decrease in carrier concentration and the removal of defects as a result of the higher temperature anneals.

Figure 2 compares an atomic profile $\left(600{ }^{\circ} \mathrm{C}\right)$ with two carrier profiles after annealing the single energy $(5 \mathrm{keV}) \mathrm{im}-$ plants at 600 and $800{ }^{\circ} \mathrm{C}$ for $10 \mathrm{~s}$. The two carrier profiles are very similar. However, it is only possible to measure part of the carrier distribution because of the close proximity of the $n^{+} / p$ junction and the high resistance associated with the resulting depletion region. A peak carrier concentration of $3-4 \times 10^{20} \mathrm{~cm}^{-3}$ is obtained, which is similar to the value reported by Nylansted-Larsen et al. ${ }^{6}$ for $80 \mathrm{keV}$ implants. The atomic profiles are identical for these two annealing temperatures, whilst the carrier concentration is also the same within experimental error. Thus diffusion of antimony is absent under these annealing conditions. The atomic profile for the as implanted material (not shown) agrees with those measured after annealing at $600{ }^{\circ} \mathrm{C}$ (Figs. 2 and 3) and $800{ }^{\circ} \mathrm{C}$ (not shown).

Complete electrical profiles have been measured using the double implant $(5 \mathrm{keV}+70 \mathrm{keV})$ and Fig. 3 illustrates the differences between three profiles which quantifies typical variations observed and the reproducibility of the profiling technique. Here the peak carrier concentration is lower (about $2 \times 10^{20} \mathrm{~cm}^{-3}$ ) than the value measured for the single energy implant (Fig. 3). This may be due to the better sensitivity that we have using the double implant scheme or it may be due to a net reduction in vacancy concentration in the near surface region as a result of the deeper implant, which reduces the carrier concentration. However, we have found peak carrier concentrations of about $2 \times 10^{20} \mathrm{~cm}^{-3}$ for $40 \mathrm{keV}$ implants. $^{7}$ The carrier profiles (Fig. 3) follow the atomic profile quite closely in the tail region. The deeper, $70 \mathrm{keV}$ antimony implant has not become fully activated, but

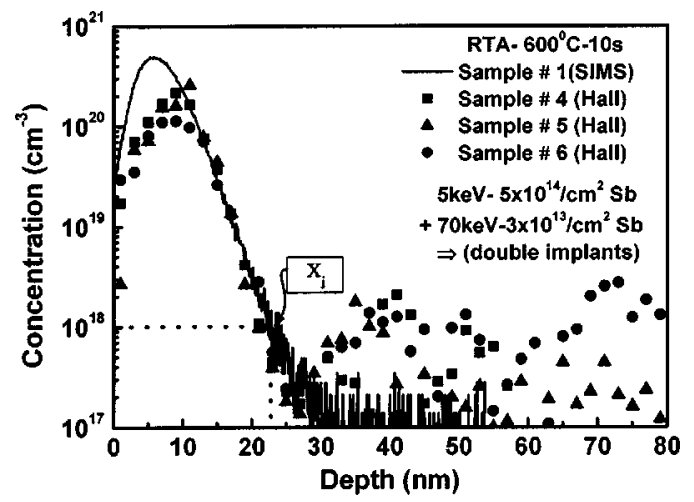

FIG. 3. Three carrier concentration profiles for double implants: $5 \mathrm{keV} \mathrm{Sb}^{+}$ at dose of $5 \times 10^{14} \mathrm{~cm}^{-2}$ and $70 \mathrm{keV} \mathrm{Sb}$ at dose of $3 \times 10^{13} \mathrm{~cm}^{-2}$. Also included is a SIMS atomic profile. The annealing temperature was $600{ }^{\circ} \mathrm{C}$ for $10 \mathrm{~s}$. $X_{j}$ denotes the junction depth of $22 \pm 1 \mathrm{~nm}$.

has produced carrier concentrations in the range up to 2 $\times 10^{18} \mathrm{~cm}^{-3}$. Thus we can confidently conclude that the junction depth, defined here as the depth at which the carrier concentration falls to $10^{18} \mathrm{~cm}^{-3}$, is $22 \pm 1 \mathrm{~nm}$, which agrees with the atomic profiles of Figs. 2 and 3.

For all samples, the uniformity of the oxidation process is quantified by measuring the ratio of the sheet resistance between each pair of contacts following each oxidation step. For ideal samples this ratio should be unity and remain so until the end of the profile determination. Large changes in the ratio $(>1.5)$ are sometimes observed and in these cases the results are ignored, because the oxidation process has not remained uniform with depth.

We have demonstrated a modified differential Hall effect technique for the measurement of carrier profiles of shallow layers in silicon. The use of a higher energy $(70 \mathrm{keV}) \mathrm{im}-$ plant enables the measurement of the complete electrical profile for $5 \mathrm{keV}$ antimony. This technique has required the development of a reproducible oxidation process for removing material in order to facilitate the differential Hall measurements. The junction depth of $22 \mathrm{~nm}$ was essentially that of the as-implanted atomic profile, determined by SIMS, so no measurable diffusion of the antimony occurred below $800{ }^{\circ} \mathrm{C}$, where optimum electrical results were obtained.

The authors would like to thank the Kuwait Government, the University of Surrey Ion Beam Centre, and the UK Engineering and Physical Sciences Research Council for their financial support of this project. We also thank Dr. S. Ahmed and Dr. P. Too for valuable advice and discussions.

${ }^{1}$ H. Iwai, IEEE J. Solid-State Circuits 34, 357 (1999).

${ }^{2}$ R. Dejule, Semicond. Int. 20, 54 (1997).

${ }^{3}$ K. Shibahara, IEICE Trans. Electron. E85-C, 1091 (2002).

${ }^{4}$ G. A. Sai-Halasz, K. T. Short, and J. S. Williams, IEEE Electron Device Lett. 6, 285 (1985).

${ }^{5}$ N. D. Young and M. J. Hight, IEE Elec. Lett. 21, 1044 (1985).

${ }^{6}$ A. Nylandsted-Larsen, F. T. Pedersen, G. Weyer, R. Galloni, R. Rizzoli, and A. Armigliato, J. Appl. Phys. 59, 1908 (1986).

${ }^{7}$ T. Alzanki, R. Gwilliam, N. Emerson, Z. Tabatabaian, C. Jeynes, and B. J. Sealy, Semicond. Sci. Technol. 19, 728 (2004). 